\title{
The Effect of English Vocabulary Learning with Digital Games and its Influencing Factors based on the Meta- Analysis of 2,160 Test Samples
}

\author{
https://doi.org/10.3991/ijet.v15i17.11758 \\ Qing Wu, Jinwei Zhang \\ Wuhan University Institute of Education Sciences, Wuhan, China \\ Chuanyi Wang $(\bowtie)$ \\ Tsinghua University Institute of Education, Beijing, China \\ wangchuanyi1128@163.com
}

\begin{abstract}
In the digital era, digital games attract more attention in the academic circle, and especially in the field of English vocabulary learning, the use of digital games have been widely applied. However, a scientific and comprehensive conclusion has not been drawn in the studies regarding the English vocabulary learning effect. This study was conducted based on the dissertations that provided the effects of English vocabulary learning through digital games collected from English-language databases such as WOS and ERIC throughout 2008-2018. Through a meta-analysis, the heterogeneity between the studies was minimized, and the data were analyzed and visualized according to the effect size. The studies found that digital games played an significant role in promoting English vocabulary learning; from the five influencing factors, namely the learning stage, game-aided teaching method, native language background, game platform, and game scenario, the influencing factors were summarized by referring to the standards for effect sizes; it was found that the native language background had the most prominent impact, while the negative transfer of native language has hindered the vocabulary learning of Asian students. The impacts of the game platform, game-aided teaching method, and game scenario have weakened successively. Finally, in order to promote the high-quality application of digital games into education and teaching, there was a need to continuously optimize the internal mechanism so as to drive the iterative upgrading of the games and create a contextualized and intelligent digital game.
\end{abstract}

Keywords-Digital game, English vocabulary, meta-analysis.

\section{Introduction}

Digital games are those designed and developed relying on the computer technology and implemented through digital equipment as a platform. "Computer games", "video games", "online games", "mobile games" and other games are included into digital games. This paper defines the term "digital games" specifically as those devel- 
oped for the purpose of promoting teaching and learning, as a form of educational games [1]. China's Plan towards Education Modernization 2035 states that one of top 10 strategic missions is to "accelerate the transformation of the information era", and points out that "modern technology needs to be applied to accelerate the reform of the talent training mode and organically combine large-scale education with individualized training."

As one of the trends for the development of education information, digital games are worthy of continuous attention. In the academic field, it is argued whether digital games can facilitate English vocabulary learning. On the one hand, the role of digital games has been affirmed in terms of its satisfactory performance in enhancing the students' learning motivation; on the other hand, the real facts are conflicting with these positive results, and there have been debates over the applicable target users and game settings. Therefore, the meta-analysis method was adopted in this study, and the factors influencing the English vocabulary learning effect are mainly discussed on the basis of answering whether the digital games facilitate foreign language vocabulary learning. Accordingly, this paper was also aimed to guide the teachers on how to reasonably practice the digital-game-aided teaching and promote the deep application of digital games in the field of education, from the transformation of tool availability towards the view of broader educational value and learning mechanism.

\section{$2 \quad$ Literature Review}

At present, there are two opinions regarding the studies on the impacts of digital games on English vocabulary learning: digital games can facilitate English vocabulary learning; digital games bring little impact on vocabulary learning.

The first view is that digital games can improve the learning effects by enhancing the learning experience and stimulating learning interests. For example, Sahrir [2] designed and developed a web-based vocabulary game for beginner learners of the English language so as to provide interactive learning experience for the learners, and to allow the learners to better memorize the vocabulary with stronger interest; Wang et al [3] stated that the digital games designed according to meaningful learning materials available in daily life contributed to the development of listening and speaking skills on the basis of mobilizing the learners' motivation; Franciosi [4] conducted a quasi-experiment in Nihon University. The experimental group used an online vocabulary learning application (Quizlet) and an online game, while the control group only used the vocabulary application. It was later found that the experimental group performed better than the control group in the delay test. The results showed that the digital games could promote long-term vocabulary memory; Cerezo [5] developed a mobile game based on holographic technique to help Spanish-speaking children practice basic English vocabulary pronunciation. The test results showed that, compared with the traditional classroom teaching methods, the games had a significant impact in stimulating children's learning motivation and helped to improve their academic performance. 
The second view is that digital games have a negative impact on English vocabulary learning, and especially significant differences exist in the gameplay experience and applicable age of the target users. Ebrahimzadeh [6] believed that, if knowledge was acquired in video games, although students performed well in the short term, due to their attraction towards this novel form, while achieving very little of the expected improvements; DeHaan [7] believed that video games would have a negative impact on English vocabulary learning. High interactivity of computer games brought additional cognitive load, and resulted in the forgetting of a large number of vocabulary; Aghlara [8] pointed out that, when lower grade students learned English vocabulary, intuitive games such as word cards and board games had better effects than computer games.

In summary, more scientific and comprehensive study conclusions were not drawn regarding whether the digital games had a positive impact on English vocabulary learning. Moreover, many factors, such as native language background, game-aided teaching method, vocabulary difficulty, as well as the game itself, would also significantly affect the learning effect. Therefore, a meta-analysis method was adopted in this study so as to discuss the impacts of digital games on English vocabulary learning and explore the factors significantly influencing the vocabulary learning effect.

\section{$3 \quad$ Research Method and Process}

\subsection{Research method and tool}

Meta-analysis refers to the application of specific design and statistical methods for the overall and systematic qualitative/quantitative analysis of previous research results. Its advantages over the traditional review methods lie in that meta-analysis is unlimited by the number of studies; the analysis process is rigorous and scientific, while the research conclusions are complete and objective. During a meta-analysis, the data are extracted from published literatures, such as sample size, mean and standard deviation; in addition, an effect size is given according to the specific methods and calculation formulas. Finally, the intensity of each variable is compared and analyzed based on this effect size.

The effect value has two functions, namely acquiring the functions of independent variables based on the effect size and providing the comprehensive effects of an independent variable in a series of experiments after obtaining the mean of many effect sizes. During the mean difference tests for two independent samples, the standardized mean difference (SMD) of the experiment group and control group is generally taken as an effect size. In this study, Review Manager 5.3 (Revman) was used for data extraction and analysis, effect size calculation, heterogeneity test, and publication bias. The results were then illustrated as a random effect model and a funnel plot. 


\subsection{Research process}

Literature resources and screening: In this study, the Web of Science, ERIC, Elsevier, and Google Scholar English-language databases were used for searching using the input form of TI (title) = "game" and "vocabulary". The earliest papers that focused on game-based learning was published by Prensky in 2001. A total of 446 English periodicals were collected when the search time-range was set to 2001 - 2018, and the search results were imported into NoteExpress in the form of bibliography for fine screening. The literature screening conditions were set as follows:

1. The studies must be based on digital games

2. The research objects study English vocabulary

3. The study is an experiment or quasi-experiment

4. The study must concentrate on the impacts of digital games on English vocabulary learning

5. The research objects include experimental group and control group, and the specific number has also been stated

6. The research data meet the meta-analysis conditions, such as mean and standard deviation

7. The study objects exclude students with SEN or learning disorder

According to the above standards, a total of 55 dissertations were included into the meta-analysis after the strict screening. 2,160 samples were tested, and 82 effect sizes which met the meta-analysis requirements were obtained (some study samples contained multiple effect sizes).

Feature value encoding: In addition to the basic information of the research, in order to explore the factors influencing the English vocabulary learning effect, there was also a need to extract the eigenvalues of each article for encoding. The specific encoding rules included six aspects, as shown in Table 1:

Table 1. Feature Value Encoding

\begin{tabular}{|c|l|l|}
\hline SN & \multicolumn{1}{|c|}{ Feature coding } & \multicolumn{1}{|c|}{ Classification } \\
\hline 1 & Learning stage & $\begin{array}{l}\text { Pre-school, primary school, secondary school, and univer- } \\
\text { sity }\end{array}$ \\
\hline 2 & Game-aided teaching method & $\begin{array}{l}\text { Pure classroom teaching (only in classrooms), self-learning } \\
\text { (after class), mixed learning (in classrooms and after class) }\end{array}$ \\
\hline 3 & Native language & $\begin{array}{l}\text { Asian (Chinese and Japanese), Middle Eastern (Iranian, } \\
\text { Arabic and Turkish), Southeast Asian (Thai, Malay, and } \\
\text { Indonesian), European (Spanish, Dutch, and Swedish) }\end{array}$ \\
\hline 4 & Game platform & Computer and mobile devices \\
\hline 5 & Game scenarios & General, moderate, and high \\
\hline
\end{tabular}

Analysis framework: This paper explored the overall impact of digital games on English vocabulary learning. The following analysis framework was proposed based on various moderator variables (Figure 1). 


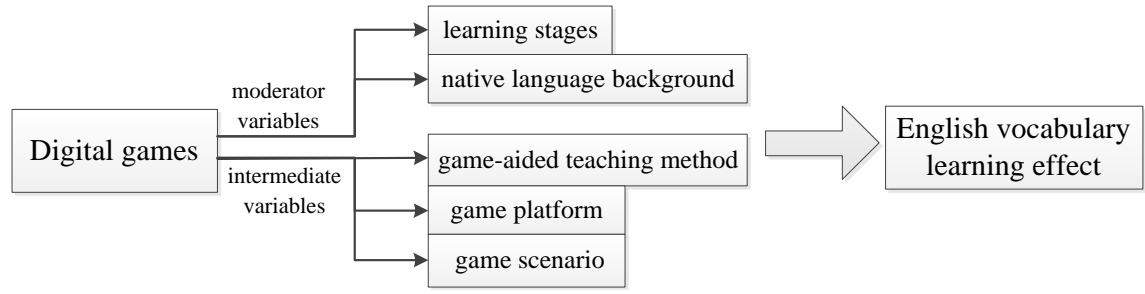

Fig. 1. The meta-analysis framework

\section{Data Analysis Results}

\subsection{Heterogeneity test and publication bias}

Heterogeneity test: Heterogeneity inevitably exists during various studies due to the differences in sample selection, implementation process, research method, and evaluation standards, etc. The purpose of the heterogeneity test is to check whether the results of each independent study are amalgamable. The heterogeneity determines the selection of the analytical models. For small heterogeneity, a fixed effect model is used. For large heterogeneity, a random effect model is more reliable. Generally, the heterogeneity is determined according to the I 2 value. As shown in Table 2, when the I2 was 93\% (I2>75\% indicates significant heterogeneity), the sample heterogeneity was high, and many potential influencing factors existed. Therefore, a random effect model was selected to combine effect sizes.

Table 2. Verification of the overall effect of digital games for English vocabulary learning

\begin{tabular}{|l|c|c|c|c|c|}
\hline & d & $\mathbf{9 5 \%}$ CI & df & $\mathbf{I}^{\mathbf{2}}$ & P \\
\hline Random effect model & 0.94 & $0.69,1.20$ & \multirow{2}{*}{58} & \multirow{2}{*}{$93 \%$} & $<0.00001$ \\
\hline Fixed effect model & 0.84 & $0.77,0.90$ & & & \\
\hline
\end{tabular}

Bias test: It is easier to publish the papers with positive results than those with negative results in similar studies; such papers also feature shorter publication cycle and higher influencing factors for periodicals publication, while the papers are also cited more frequently than those with negative results [9]. It easily results in the inability to systematically represent the overall research situations of this field by the collected literature, hence affecting the meta-analysis results. Therefore, a publication bias test was required. During a meta-analysis, a funnel plot is usually used to identify the bias. In Figure 3, the points represented the effect sizes of each sample, and the center dash line represented the mean effect sizes. It could be seen from the figure that these points were relatively evenly distributed on either side of the dotted line, and most of them were at the upper end of the "inverted funnel", which indicated that there was a small possibility of publication bias during the study and that the study results were highly reliable. 


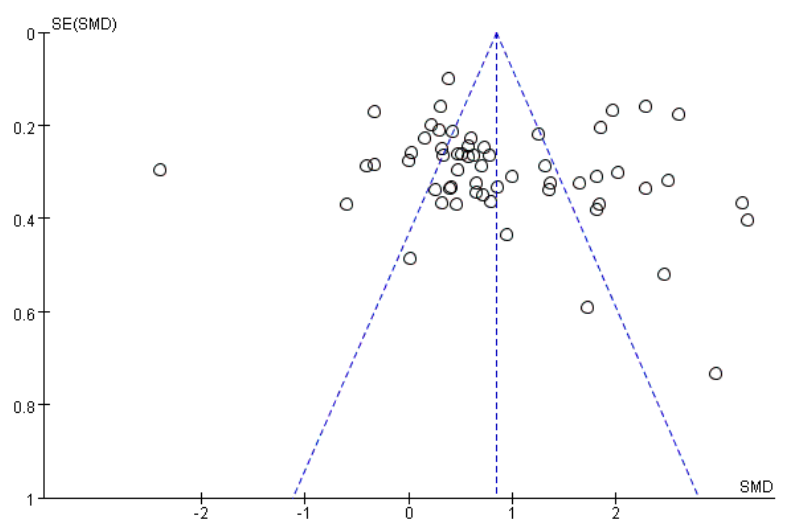

Fig. 2. Funnel plot for the publication bias test

\subsection{Overall effect size analysis}

The overall effect test showed that the learning effect was significantly improved after the application of digital games into English vocabulary learning. According to Cohen's effect size determination standard [10], when the effect size was 0.2 , the effect is small; when $d=0.5$, the effect is moderate; when $d=0.8$, the effect is significant. In Table 2, the combined effect size d of the random effect model was 0.94 , while the upper and lower limits were 0.69 and 1.20 respectively at the $95 \%$ confidence interval, which indicated that the overall effect size was reasonable and that it was statistically significant at the 0.05 level $(\mathrm{p}<0.05)$. The effect size of the study ranged between 0.8 and 1.0, which indicated that the digital games had greater impacts on English vocabulary learning and could effectively improve the learning effect.

\subsection{The influencing factors of digital games for English vocabulary learning}

Due to large heterogeneity between studies after combination, it was necessary to combine the feature values of the studies so as to explore the factors influencing the English vocabulary learning effect.

Learning stage: In overall, the learning stage presented no significant difference in learning effects, and all of them had positive impacts on English vocabulary learning. According to their respective effect sizes, the effect size for the pre-school stage was 0.5 , showing moderate effects; while other learning stages were significantly stronger than the pre-school stage in the learning effect; the effect sizes of the primary school, secondary school and university stages were greater than 0.8 , which indicated that the games had great impacts in improving English vocabulary learning, especially in primary school $(\mathrm{d}=0.93)$ and university $(\mathrm{d}=0.96)$ stages. 
Table 3. Impact of learning stages on English vocabulary learning effect

\begin{tabular}{|l|c|c|c|c|c|}
\hline \multicolumn{1}{|c|}{ Learning Stage } & $\mathbf{N}$ & $\mathbf{d}$ & $\mathbf{9 5 \%} \mathbf{C I}$ & $\mathbf{Z}$ & $\mathbf{P}$ \\
\hline Pre-school & 5 & 0.50 & $0.26,0.75$ & 4.01 & $<0.0001$ \\
\hline Primary school & 17 & 0.93 & $0.48,1.39$ & 4.02 & $<0.0001$ \\
\hline Secondary school & 14 & 0.89 & $0.45,1.33$ & 3.97 & $<0.0001$ \\
\hline University & 20 & 0.96 & $0.44,1.49$ & 3.60 & 0.0003 \\
\hline
\end{tabular}

Game-aided teaching method: The effect sizes of three game-aided teaching methods ranged between 0.6 and 1.0, which indicated that any learning mode had a positive impact on English vocabulary learning. From the perspective of their respective effects, the effect of these three kinds of game-aided teaching methods were as follows: self-learning $(\mathrm{d}=1.05)>$ classroom learning $(\mathrm{d}=0.84)>$ mixed learning $(\mathrm{d}=0.68)$, which indicated that self-learning had the best effect and had a positive impact on English vocabulary learning for the students at various learning stages (see Table 5). Therefore, this could further explain why self-learning could better improve the English vocabulary learning and reflect the students' hopes to master their own learning progress within a certain period.

Table 4. Impact of game-aided teaching method on English vocabulary learning effect

\begin{tabular}{|l|c|c|c|c|c|}
\hline Game-aided teaching method & $\mathbf{N}$ & $\mathbf{d}$ & $\mathbf{9 5 \%} \mathbf{C I}$ & $\mathbf{Z}$ & $\mathbf{P}$ \\
\hline Classroom learning & 9 & 0.84 & $0.39,1.29$ & 3.69 & 0.0002 \\
\hline Self-learning & 36 & 1.05 & $0.68,1.42$ & 5.61 & $<0.0001$ \\
\hline Mixed learning & 14 & 0.68 & $0.23,1.14$ & 2.94 & 0.003 \\
\hline
\end{tabular}

Table 5. Impact of self-learning stages on English vocabulary learning effect

\begin{tabular}{|l|c|c|c|c|c|}
\hline \multicolumn{1}{|c|}{ Self-learning Stage } & N & d & 95\% CI & Z & P \\
\hline University & 13 & 0.80 & $0.02,1.58$ & 2.01 & 0.04 \\
\hline Secondary school & 8 & 0.83 & $0.19,1.47$ & 2.54 & 0.01 \\
\hline Primary school & 8 & 1.26 & $0.52,2.00$ & 3.35 & 0.0008 \\
\hline
\end{tabular}

Native language: The native language background is an important factor influencing the English vocabulary learning effect. In different countries and regions, the overall effect size of the Asian regions was 0.62, showing moderate effects; the overall effect size of the students in the Middle East was 1.33, among which the digital games for Arabic-speaking students had moderate learning effect $(d=0.56)$, lower than Iranian-speaking $(\mathrm{d}=1.38)$ and Turkish-speaking students $(\mathrm{d}=1.41)$. The learning effect of different countries and regions are as follows: Southeast Asia $(\mathrm{d}=2.02)>$ Middle East $\quad(\mathrm{d}=1.33)>$ English-speaking countries $\quad(\mathrm{d}=0.8)>$ Asia $(d=0.62)>$ Europe $(d=0.53)$. It indicated that digital games played a significant role in promoting English vocabulary learning for the students in Southeast Asian and Middle Eastern countries. 
Table 6. Impact of country and native language on English vocabulary learning effect

\begin{tabular}{|c|c|c|c|c|c|c|c|}
\hline \multicolumn{2}{|c|}{ Region and Country } & $\mathbf{N}$ & d & $95 \% \mathrm{CI}$ & $\mathbf{Z}$ & $\mathbf{P}$ & $\begin{array}{l}\text { Inter-group } \\
\text { Effect Size }\end{array}$ \\
\hline \multirow{2}{*}{ Asia } & China & \multirow{2}{*}{24} & \multirow{2}{*}{0.62} & \multirow{2}{*}{$0.16,1.09$} & \multirow{2}{*}{2.62} & \multirow{2}{*}{0.009} & \multirow{12}{*}{$\begin{array}{l}\mathrm{Chi}^{2}=12.97(\mathrm{P}= \\
0.01)\end{array}$} \\
\hline & Japan & & & & & & \\
\hline \multirow{3}{*}{ Middle East } & Iran & 29 & 1.38 & $0.87,1.89$ & \multirow{3}{*}{6.29} & \multirow{3}{*}{$<0.001$} & \\
\hline & Turkey & 3 & 1.41 & $0.86,2.14$ & & & \\
\hline & Saudi Arabia & 5 & 0.56 & $0.35,0.77$ & & & \\
\hline \multirow{3}{*}{$\begin{array}{l}\text { Southeast } \\
\text { Asia }\end{array}$} & Thailand & \multirow{3}{*}{5} & \multirow{3}{*}{2.02} & \multirow{3}{*}{$0.84,3.20$} & \multirow{3}{*}{3.35} & \multirow{3}{*}{$<0.001$} & \\
\hline & Indonesia & & & & & & \\
\hline & Malaysia & & & & & & \\
\hline \multirow{3}{*}{ Europe } & Spain & \multirow{3}{*}{8} & \multirow{3}{*}{0.53} & \multirow{3}{*}{$0.18,0.89$} & \multirow{3}{*}{2.96} & \multirow{3}{*}{0.003} & \\
\hline & \begin{tabular}{|l|} 
Netherlands \\
\end{tabular} & & & & & & \\
\hline & Sweden & & & & & & \\
\hline $\begin{array}{l}\text { English- } \\
\text { speaking } \\
\text { country }\end{array}$ & 1 & 5 & 0.8 & $0.20,1.40$ & 2.61 & 0.009 & \\
\hline
\end{tabular}

Game platform attributes: According to Table 7, it could be concluded that computers and mobile devices showed a significant positive impact in promoting English vocabulary learning. The effect sizes $d$ of the computers and mobile devices were 0.98 and 0.83 respectively. In contrast, computers showed slightly better learning effect, for which the reason lied in that the learners generally use computers to learn, usually in the computer room or in front of their desks. Owing to little interference from other forms of disturbances, the learners were more concentrated, and hence their learning was promoted.

Table 7. Impact of game platform on English vocabulary learning effect

\begin{tabular}{|l|c|c|c|c|c|}
\hline \multicolumn{1}{|c|}{ Game Platform } & N & d & $\mathbf{9 5 \%}$ CI & Z & P \\
\hline Computer & 45 & 0.98 & $0.68,1.28$ & 6.45 & $<0.001$ \\
\hline Mobile terminal & 14 & 0.83 & $0.34,1.31$ & 3.35 & $<0.001$ \\
\hline
\end{tabular}

Game scenario: The richness of the game scenario had different impacts on the learning effect. The effect size $d$ was 0.1 for those with richer scenarios, which indicated that games with richer scenarios had positive and significant impacts in promoting English vocabulary learning, and produced the best effects among three kinds of scenes. The richness of the game scenario was reflected in the game setting and human-computer interaction. If the scene was too rich, the complex game setting and interaction might lead to an increase in knowledge capacity. In this case, although the learners' senses were continuously stimulated, the effect was deconstructive for English vocabulary learning. Therefore, a moderate-level game scenario could better promote English vocabulary learning. 
Table 8. Impact of game scenario on English vocabulary learning effect

\begin{tabular}{|l|c|c|c|c|c|}
\hline \multicolumn{1}{|c|}{ Game scenario } & N & d & $\mathbf{9 5 \%}$ CI & Z & P \\
\hline Generally rich & 22 & 0.80 & $0.45,1.16$ & 4.39 & $<0.001$ \\
\hline Rich & 29 & 1.00 & $0.61,1.39$ & 5.01 & $<0.001$ \\
\hline Very rich & 10 & 0.91 & $0.22,1.60$ & 2.57 & 0.01 \\
\hline
\end{tabular}

\section{Conclusion and Discussion}

Meta-analysis was performed for the horizontal and vertical analysis of 55 English periodicals focusing on digital-games-aided English vocabulary learning published from 2008 to 2018. According to the five aspects of learning stage, game-aided teaching method, native language background, game platform, and game scenario, the factors influencing the learning effect were analyzed in depth. The study found that:

1) The overall effect size was 0.94 , which indicated that digital games had a significantly positive impact on English vocabulary learning

2) The learning stage had no significant impact

3) From the perspective of game-aided teaching, self-learning had the best English vocabulary learning effect

4) From the perspective of native language background, the digital games had a positive role in promoting learning for students in Southeast Asia and Middle East, but had moderate learning effect in Asia

5) From the perspective of game platform, computers had more prominent learning effect than the mobile devices

6) From the perspective of game scenario, the games with rich scenarios had the best vocabulary learning effect.

\subsection{The positive effect of digital games on English vocabulary learning}

In overall, digital games played a significant role in improving the English vocabulary learning effect. This indicates that digital games had certain advantages and values for cognitive memory-based learning. Digital games enrich the learning experience compared to the traditional English vocabulary learning methods. With the popularization of the game, the element of seriousness in knowledge acquisition has been consciously weakened, and vocabulary memorization is no longer boring. Secondly, digital games stimulate learning motivation, and the learners' learning effect is enhanced by continuously enhancing the motivation; finally, the usage of digital games is unlimited to the time and place, thus increasing the usage rate of the games. In general, digital games allows the learners to allocate more energy into learning, thus achieving better learning effect. 


\subsection{Factors influencing vocabulary learning effect}

Table 9. Effect Sizes of Various Influencing factors

\begin{tabular}{|l|c|c|c|c|}
\hline \multicolumn{1}{|c|}{ Influencing factor } & $\mathbf{d}$ & $\mathbf{9 5 \%} \mathbf{C I}$ & $\mathbf{Z}$ & $\mathbf{P}$ \\
\hline Learning stage & 0.89 & $0.64,1.14$ & 6.49 & $<0.00001$ \\
\hline Game-aided teaching method & 0.93 & $0.68,1.18$ & 7.17 & $<0.00001$ \\
\hline Native language background & 0.97 & $0.72,1.22$ & 7.64 & $<0.00001$ \\
\hline Game platform & 0.94 & $0.69,1.20$ & 7.30 & $<0.00001$ \\
\hline Game scenario & 0.91 & $0.66,1.16$ & 7.21 & $<0.00001$ \\
\hline
\end{tabular}

According to the analysis results of various adjustment variables, influencing factors were categorized into 4 categories, and were sorted according to the specific influence as follows: native language background $(\mathrm{d}=0.97)>$ game platform $(\mathrm{d}=0.94)>$ game-aided teaching method $(\mathrm{d}=0.93)>$ game scenario $(\mathrm{d}=0.91)$.

Firstly, in foreign language learning, everyone will be affected by different levels of native language transfer. When the target language is similar with native language culture background, a positive transfer of native language will occur during learning. When great differences exist between target language and native language in linguistic structure and features, the language habits of the native language will inhibit the learning of the target language[50], causing negative transfer. Besides, the learners are affected by the thinking mode of native language[51]. When the language span is too large, a "thinking gap" will exist, and the learning process will become more rigid. Asian students usually live under a monotonous and less-substantial linguistic environment, and especially since the Chinese thinking affects the extraction of vocabulary, the students have poorer learning effect than those in other regions.

Secondly, the self-learning based game-aided teaching method can better promote learning. There are two main reasons: firstly, compulsory education is based on classroom teaching, while self-learning will give a fresh sense to the students, which stimulates learning. Secondly, in most English classes, the teaching content mainly focuses on the texts in the textbooks. The teachers generally start with vocabulary and analyze the texts word-by-word. The students learn knowledge under a very passive state, which results in the unilateral imparting of knowledge in the English classes. At the same time, because of different learning levels of the students in the classrooms, the teaching effect is significantly reduced. Hence, for knowledge learning mainly involving vocabulary memory, self-learning gives sufficient initiative to the students. The students can adjust the learning time according to their own ability and learning needs, thus maximizing the learning effect.

Moreover, both learning platforms can effectively promote learning, but computers bring better learning effect, for which the reason lies in that computers perform better in enhancing student concentration, thus improving the learning efficiency. In contrast, the physical attributes of the platform affect the output and use of information. The display screens of computers are much larger than that of mobile devices, and more information can be displayed. The operation of the mouse and keyboard is more complicated than the operation of clicking a small screen. The platform adaptation to the environment also affects the learning input. Computer equipment occupies a cer- 
tain amount of space. The learning environment is stable and closed, so that the learners are not easily interfered during the relatively concentrated period. Owing to the flexibility of handheld devices, the learning environment is unlimited, which leads to the sporadicity and shortness of the actual learning time.

The richness of game scenarios affects the English vocabulary learning effect. The richness of game scenarios is not directly proportional to the learning effect. According to the information processing theory, the total cognitive load shall be controlled within the scope of working memory, otherwise the learning effect of the students will decrease. Although the complicated and cumbersome game scenarios seem to mobilize the enthusiasm of the students, the over-saturated images bring visual pressure, and the students cannot quickly screen and process the information, resulting in attention distraction, heavier cognitive load and poorer learning effect.

Finally, in addition to pre-school children, the learners can have better learning effect at different learning stages if they learn the vocabulary in the digital games. It is clear that, digital games have a significant role in improving the English vocabulary learning effect, and are widely applicable to the learners of all ages. The reason why preschool children have poor learning effect lies in that preschool children have a low cognitive level and are easily attracted by rich digital games forms, so that they ignore the essence of English vocabulary learning.

\section{Recommendations}

After we analyzed the impacts of digital games on vocabulary learning and its influencing factors, we would look forward to the application prospect of digital games in the field of education based on the students' cognitive development, game-aided teaching methods and other features.

\subsection{Promotion of application of digital games into English teaching}

In view of the impacts of digital games on English vocabulary learning, digital games shall be applied into reading, writing, translation and other fields. Compared with basic cognitive learning, the training of advanced skills is more challenging, so the teachers shall make full use of the interactive features of digital games and select corresponding games aided learning methods according to the students' cognitive development level. During game-aided teaching, the teachers shall reduce unnecessary guidance and give full play to students' initiative. With the innovative application of technology in the field of education, AR games are beginning to integrate into the teaching field, especially the immersion is significantly increased in the contextualized and immersive role-playing games, and AR technology can effectively expand the language communication channel without limitation on time and space. Under the close combination between high-tech technology and curriculum design, the teachers can receive feedback from the learners in a clearer and more intuitive way so as to adjust the teaching methods. Besides, the breadth and depth of technology application shall be strictly controlled so as to prevent technology abuse. 


\subsection{Digital game optimization mechanism}

The biggest difference between digital games and learning applications lies in knowledge presentation. The knowledge in the learning applications is generally classified according to the difficulty of the modules, and its essence is to electronicize the contents of the books. However, digital games do not directly present all knowledge. The students can obtain knowledge by completing a particular virtual task or series of virtual tasks in a complete scene. The learning motivation will tend to decline over time in the games, and less determined learning willingness and attitude will affect the stability and persistence of the learning process. Sung et al. believed that [52] if the design of educational computer games lacked appropriate learning strategies, this might not produce the expected results and bring poor learning effect, so learning motivation and strategies cannot be ignored. Hence, in order to continuously drive the learning motivation, we need to continuously optimize the development, application and evaluation mechanism of the games, vigorously promote the iterative upgrade of digital games at a macro level, select the high-quality media platform at a micro level, design and develop rich learning resources, and skillfully use the games elements, receive feedback in a timely manner for design adjustment and improvement, and build a contextualized and intelligent digital game based on knowledge capacity.

\subsection{Establishment of sound learning mechanism}

According to the educational nature of digital games, as the learners are the subject, the digital games shall fully serve the learners, and all designs of the games shall match the needs of the learners and fit the actual teaching scenes. For example, in China's English classes, the teachers prefer to Chinese teaching, so that the students cannot learn English in a purely real English environment. In addition, the students learn the books in most of the time, and the students have poor comprehensive expression ability due to lack of oral practice. Lin's experiments proved that, if the flipped game-aided teaching method was adopted, the students' writing errors could be reduced, and the students' English writing ability could be improved[53]. Therefore, for Chinese students, the teachers need to change the teaching methods and adjust the elements for classroom teaching, and simulate real scenes by introducing rich and diverse contexts so as to enhance the sense of immersion of the students, thus correcting the phenomenon of "holding one's tongue" in traditional classrooms. For classrooms with low participation, the games mechanisms such as medals and points of competitive games are introduced to stimulate students' learning enthusiasm and create a healthy competition atmosphere.

\section{$7 \quad$ References}

[1] Wang Bin and Wu Zhongjie. (2012). Thoughts on Foreign Language Learning in Educational Games - Based on RPG Games. Modern Educational Technology, 22(01):77-79.

[2] Sahrir, M. S. and N. A. Alias, et al. (2012). Employing design and development research (DDR) approaches in the design and development of online Arabic vocabulary learning 
games prototype.turkish online journal of educational technology 11 (2): 108-119. https://doi.org/10.4018/978-1-61350-198-6.ch022

[3] Wang, S. Y. and G. J. Hwang, et al. (2015). Development of a Contextual Game for Improving English Vocabulary Learning Performance of Elementary School Students in Taiwan. T. Matsuo, K. Hashimoto, T. Mine and S. Hirokawa. New York, IEEE: 268-272.

[4] Franciosi, S. J. and J. Yagi, et al. (2016). The Effect of a Simple Simulation Game on Long-Term Vocabulary Retention. Calico Journal 33 (3): 355-379.

[5] Cerezo, R. and V. Calderón, et al. (2019). A holographic mobile-based application for practicing pronunciation of Basic English vocabulary for Spanish speaking children. International Journal of Human-Computer Studies 124: 13-25. https://doi.org/10.10 16/j.ijhcs.2018.11.009

[6] Ebrahimzadeh, M. and S. Alavi (2016).Motivating EFL students: E-learning enjoyment as a predictor of vocabulary learning through digital video games.COGENT EDUCATION 3 (UNSP 1255400). https://doi.org/10.1080/2331186x.2016.1255400

[7] DeHaan, J. and W. M. Reed, et al. (2010). The Effect of Interactivity with a Music Video Game on Second Language Vocabulary Recall: Language Learning \& Technology.A Refereed Journal for Second and Foreign Language Educators 14 (2): 74.

[8] Aghlara, L. and N. H. Tamjid (2011). The effect of digital games on Iranian children's vocabulary retention in foreign language acquisition. Procedia Social and Behavioral Sciences. Z. Bekirogullari. Amsterdam, Elsevier Science bv. 29. https://doi.org/10.10 16/j.sbspro.2011.11.275

[9] Sun Siqin, Chu Cunkun and Han Fengxuan. (2017). Study on Impacts of Grey Literature on Publication Bias.Modern Information,37(12):48-51.

[10] Cohen J. (1988). Statistical power analysis for the behavioral science. Hillsdale, NJ: Lawrence Erlbaum Associates: 19-74.

[11] Wu, T. and Y. Huang (2017). A Mobile Game-Based English Vocabulary Practice System Based on Portfolio Analysis. Educational technology \& Society 20 (2): 265-277.

[12] Franciosi, S. J. (2017). The Effect of Computer Game-Based Learning on FL Vocabulary Transferability. Educational Technology \& Society 20 (1): 123-133.

[13] Gibbon, J. M. and S. Duffield, et al. (2017). Effects of Educational Games on Sight Word Reading Achievement and Student Motivation. Journal of Language and Literacy Education 13 (2).

[14] Ramon Calvo-Ferrer, J. (2017). Educational games as stand-alone learning tools and their motivational effect on L2 vocabulary acquisition and perceived learning gains. British journal of educational technology 48 (2): 264-278. https://doi.org/10.11 $\underline{11 / \text { bjet. } 12387}$

[15] Ahmadmian, M. and M. Amerian, et al. (2015). A Comparative Study of Paper-Based and Computer-Based Contextualization in Vocabulary Learning of EFL Students.Advances in Language and Literary Studies 6 (2): 96-102. https://doi.org/10.7575/aiac.alls.v.6n.2p.96

[16] Ali Mohsen, M. (2016). The Use of Computer-Based Simulation to Aid Comprehension and Incidental Vocabulary Learning. Journal of Educational Computing Research 54 (6): 863-884. https://doi.org/10.1177/0735633116639954

[17] Ashraf, H. and F. G. Motlagh, et al. (2014). The Impact of Online Games on Learning English Vocabulary by Iranian (Low-intermediate) EFL Learners. Procedia Social and Behavioral Sciences. K. Sadeghi, S. Modirkhameneh, P. Alavinia and Z. A. Khonbi. AMSTERDAM, ELSEVIER SCIENCE BV. 98: 286-291. https://doi.org/10.1016/j.sbs pro.2014.03.418 
[18] Aslanabadi, H., \& Rasouli, G. (2013). The effect of games on improvement of Iranian EFL vocabulary knowledge in kindergartens. International Review of Social Sciences and $\mathrm{Hu}-$ manities, 6(1), 186-195.

[19] Benoit, J. M. (2017). The effect of game-based learning on vocabulary acquisition for middle school English language learners.

[20] Cerezo, R. and V. Calderón, et al. (2019). A holographic mobile-based application for practicing pronunciation of basic English vocabulary for Spanish speaking children. International Journal of Human-Computer Studies 124: 13-25. https://doi.org/10.1016/j.ijhcs.20 $\underline{18.11 .009}$

[21] Fahim, M. and S. Sabah (2012). An Ecological Analysis of the Role of Role-play Games as Affordances in Iranian EFL Pre-university Students' Vocabulary Learning. Theory and Practice in Language Studies 2 (6). https://doi.org/10.4304/tpls.2.6.1276-1284

[22] Huang, Y. and Y. Huang (2015). A scaffolding strategy to develop handheld sensor-based vocabulary games for improving students' learning motivation and performance. ETR \& D-Educational Technology Research and Development 63 (5SI): 691-708. https://doi.org/10.1007/s11423-015-9382-9

[23] Jalali, S, \& Dousti, M. (2012). Vocabulary and grammar gain through computer educational games. Gema Online Journal of Language Studies, 12(4), 1077-1088.

[24] Letchumanan, K. and B. H. Tan, et al. (2015). Incidental Learning of Vocabulary through Computer-Based and Paper-Based Games by Secondary School ESL Learners. Pertanika Journal of Social Science and Humanities 23 (3): 725-740.

[25] Lu, F. and B. Chang (2016). Role-Play Game-Enhanced English for a Specific-Purpose Vocabulary-Acquisition Framework. Journal of Educational Technology \& Society 19 (2): 367-377.

[26] Ma, Q. and P. Kelly (2006). Computer assisted vocabulary learning: Design and evaluation. Computer Assisted Language Learning 19 (1): 15-45. https://doi.org/10.1080/09588 $\underline{220600803998}$

[27] Sandberg, J. and M. Maris, et al. (2014). The added value of a gaming context and intelligent adaptation for a mobile learning application for vocabulary learning. Computers \& Education 76: 119-130. https://doi.org/10.1016/j.compedu.2014.03.006

[28] Schuurs, U. (2012). Serious Gaming and Vocabulary Growth Research into the Effectiveness of a Serious Game upon Receptive Vocabulary. Communications in Computer and Information Science. S. DeWannemacker, S. Vandercruysse and G. Clarebout. BERLIN, SPRINGER-VERLAG BERLIN. 280: 40-46. https://doi.org/10.1007/978-3-642-33814$\underline{4} 5$

[29] Segers, E. and L. Verhoeven (2003). Effects of vocabulary training by computer in kindergarten. Journal of Computer Assisted Learning 19 (4): 557-566. https://doi.org/10.1046/j. 0266-4909.2003.00058.x

[30] Smith, G. G. and M. Li, et al. (2013). Play games or study? Computer games in eBooks to learn English vocabulary. Computers \& Education 69: 274-286. https://doi.org/10. 1016/j.compedu.2013.07.015

[31] Urun, M. F. and H. Aksoy, et al. (2017). Supporting Foreign Language Vocabulary Learning Through Kinect-Based Gaming. International Journal of Game-Based Learning 7 (1): 20-35. https://doi.org/10.4018/ijgbl.2017010102

[32] Vahdat, S., \& Behbahani, A.R. (2013). The Effect of Video Games on Iranian EFL Learners' Vocabulary Learning.

[33] Wang, S. Y. and G. J. Hwang, et al. (2015). Development of a Contextual Game for Improving English Vocabulary Learning Performance of Elementary School Students in Taiwan. T. Matsuo, K. Hashimoto, T. Mine and S. Hirokawa. New York, IEEE: 268-272. 
[34] Wei, C. and H. Kao, et al. (2018). The Effects of Competitive Gaming Scenarios and Personalized Assistance Strategies on English Vocabulary Learning. Educational Technology \& Society 21 (3SI): 146-158.

[35] $\mathrm{Wu}, \mathrm{T}$. (2018). Improving the effectiveness of English vocabulary review by integrating ARCS with mobile game-based learning. Journal of Computer Assisted Learning 34 (3): 315-323. https://doi.org/10.1111/jcal.12244

[36] Wu, T. and Y. Huang (2017). A Mobile Game-Based English Vocabulary Practice System Based on Portfolio Analysis. Educational Technology \& Society 20 (2): 265-277.

[37] Yampinij, S. and S. Kongkachuay, et al. (2010). The development of computer multimedia game-based instruction on English idioms for the 2nd educational range at Bannakhao School, IEEE. https://doi.org/10.1109/icctd.2010.5645963

[38] Yen, L. and C. M. Chen, et al. (2016). Effects of Mobile Game-Based English Vocabulary Learning APP on Learners' Perceptions and Learning Performance: A Case Study of Taiwanese EFL Learners. Proceedings of the International Conference on e-Learning. R. M. Idrus and N. Zainuddin. NR Reading, ACAD Conferences ltd: 255-262. https:// doi.org/10.1017/s0958344018000228

[39] Yip, F. W., \& Kwan, A. C. (2006). Online vocabulary games as a tool for teaching and learning English vocabulary. Educational media international, 43(3), 233-249. https://doi. org/10.1080/09523980600641445

[40] Young, S. S. and Y. Wang (2014). The Game Embedded CALL System to Facilitate English Vocabulary Acquisition and Pronunciation. Journal of Educational Technology \& Society 17 (3): 239-251

[41] Yu, Z. (2018). Comparative Effectiveness Between Game-Enhanced and Pencil-and-Paper English Vocabulary Learning Approaches. International Journal of Gaming and Computer$\begin{array}{lllll}\text { Mediated } & \text { Simulations } 10 & \text { (2): } 1-20 . & \text { https://doi.org/10.4018/ijg }\end{array}$ cms.2018040101

[42] Hwang, G. and S. Wang (2016). Single loop or double loop learning: English vocabulary learning performance and behavior of students in situated computer games with different guiding strategies. Computers \& Education 102: 188-201. https://doi.org/10.1016/ j.compedu.2016.07.005

[43] Mueller, A. and J. Son, et al. (2018). Learning English Idioms with a Web-Based Educational Game. Journal of Educational Computing Research 56 (6): 848-865. https://doi.org/10.1177/0735633117729292

[44] Zhonggen, Y. (2018). Differences in serious game-aided and traditional English vocabulary acquisition. Computers \& Education 127: 214-232. https://doi.org/10.1016/j.compedu. 2018.07.014

[45] Butler, Y. G. (2015). The use of computer games as foreign language learning tasks for digital natives. System 54: 91-102. https://doi.org/10.1016/j.system.2014.10.010

[46] Chen, M. and W. Tseng, et al. (2018). The effectiveness of digital game-based vocabulary learning: A framework-based view of meta-analysis. British Journal of Educational Technology 49 (1): 69-77. https://doi.org/10.1111/bjet.12526

[47] Franciosi, S. J. (2017). The Effect of Computer Game-Based Learning on FL Vocabulary Transferability. Educational Technology \& Society 20 (1): 123-133.

[48] Lin, H. F. (2015). Effectiveness of Interactivity in a Web-based Simulation Game on Foreign Language Vocabulary Learning. Procedia Social and Behavioral Sciences. F. Ozdamli. Amsterdam, Elsevier Science BV. 182: 313-317. https://doi.org/10.1016/j.sbs pro.2015.04.772 
[49] Tsai, Y. and C. Tsai (2018). Digital game-based second-language vocabulary learning and conditions of research designs: A meta-analysis study. Computers \& Education 125: 345357. https://doi.org/10.1016/j.compedu.2018.06.020

[50] Liu Mengqian. (2017). Study on Negative Transfer of Native Language of Middle School Students during English Vocabulary Learning: English Teacher, 17(6): 148-152.

[51] Shao Dan. (2007). Analysis on Impacts of Native Language Vocabulary during English Vocabulary Learning of Chinese Learners from the Perspective of Transfer: Science \& Technology Information (Scientific Research) (31): 226.

[52] Sung, H., et al., Experiencing the Analects of Confucius: An experiential game-based learning approach to promoting students' motivation and conception of learning. Computers \& Education, 2017. 110: p. 143-153. https://doi.org/10.1016/j.comp $\underline{\text { edu.2017.03.014 }}$

[53] Lin, C., et al., A Flipped Contextual Game-Based Learning Approach to Enhancing EFL Students' English Business Writing Performance and Reflective Behaviors. Educational Technology \& Society, 2018. 21(3SI): p. 117-131.

\section{Authors}

Qing Wu is currently an associate professor at the institute of education sciences, wuhan university, a doctor of engineering. Her research interests include big data in education and postgraduate education. She is also good at construction and application of knowledge graph based on Artificial Intelligence.

Jinwei Zhang is a postgraduate majoring in curriculum and teaching theory. She is now studying at the institute of educational sciences, Wuhan University, research interests are curriculum and information technology.

Chuanyi Wang is currently an associate professor in Tsinghua University, a doctoral candidate in management, postdoctoral candidate in higher education, postdoctoral candidate in information science, and senior research analyst. His main research areas are postgraduate education, education policy and higher education evaluation.

Article submitted 2019-09-24. Resubmitted 2020-05-19. Final acceptance 2020-05-31. Final version published as submitted by the authors. 